\title{
Contemporary Management of Recurrent Nodal Disease in Differentiated Thyroid Carcinoma
}

\author{
Shorook Na'ara, M.D., Moran Amit, M.D., Eran Fridman, M.D., and Ziv Gil, \\ M.D., Ph.D.* \\ The Head and Neck Center, Department of Otolaryngology Head and Neck Surgery, Rambam Healthcare \\ Campus, Clinical Research Institute at Rambam, Rappaport Institute of Medicine and Research, The \\ Technion, Israel Institute of Technology, Haifa, Israel
}

\begin{abstract}
Differentiated thyroid carcinoma (DTC) comprises over 90\% of thyroid tumors and includes papillary and follicular carcinomas. Patients with DTC have an excellent prognosis, with a 10-year survival rate of over $90 \%$. However, the risk of recurrent tumor ranges between $5 \%$ and $30 \%$ within 10 years of the initial diagnosis. Cervical lymph node disease accounts for the majority of recurrences and in most cases is detected during follow-up by ultrasound or elevated levels of serum thyroglobulin. Recurrent disease is accompanied by increased morbidity. The mainstay of treatment of nodal recurrence is surgical management. We provide an overview of the literature addressing surgical management of recurrent or persistent lymph node disease in patients with DTC.
\end{abstract}

KEY WORDS: Lymph nodes, persistent, thyroid neoplasm

\begin{abstract}
Abbreviations: ATA, American Thyroid Association; CND, central neck dissection; DTC, differentiated thyroid carcinoma; LND, lateral neck dissection; RAI, radioactive iodine; Tg, thyroglobulin; TSH, thyroid stimulating hormone; US, ultrasound; RLN, recurrent laryngeal nerve.

Citation: Na'ara S, Amit M, Fridman E, Gil Z. Contemporary Management of Recurrent Nodal Disease in Differentiated Thyroid Carcinoma. Rambam Maimonides Med J 2016;7 (1):eooo6. doi:10.5041/RMMJ.10233 Review

Copyright: (C) $2016 \mathrm{Na}$ 'ara et al. This is an open-access article. All its content, except where otherwise noted, is distributed under the terms of the Creative Commons Attribution License (http://creativecommons.org/licenses/by/3.o), which permits unrestricted use, distribution, and reproduction in any medium, provided the original work is properly cited.
\end{abstract}

Acknowledgement: Cindy Cohen is thanked for her editorial assistance.

Conflict of interest: No potential conflict of interest relevant to this article was reported.

* To whom correspondence should be addressed. E-mail: ziv@baseofskull.org 


\section{INTRODUCTION}

Differentiated thyroid cancer (DTC), which includes papillary and follicular cancer, accounts for the vast majority of thyroid cancers. ${ }^{1}$ Papillary thyroid carcinoma is the most common type of DTC and comprises about $80 \%-85 \%$ of all follicular cellderived thyroid cancers. ${ }^{2-5}$ Patients with DTC have excellent prognosis, with a 10-year overall survival of over $90 \% .6,7$

Generally, the outcome of DTC is usually measured by disease-specific survival, locoregional control, and postoperative complications. Regional recurrence in the cervical lymph nodes is the result of persistent disease in most cases. ${ }^{8}$ Recurrence harbors increased morbidity and mortality in highrisk groups and frequently requires surgical treatment in the form of neck dissection. ${ }^{9-12}$

This article provides an overview of the literature on the management of recurrent or persistent nodal disease in patients with DTC.

\section{NATURAL HISTORY OF RECURRENT/PERSISTENT DTC}

The treatment of primary DTC is surgical excision. Surgery often involves total thyroidectomy, with therapeutic lymph node dissection when evidence of regional spread exists. ${ }^{13}$ High-risk patients with locally invasive or metastatic disease are usually treated by surgery followed by radioactive iodine (RAI) and thyroid stimulating hormone (TSH) suppression using L-thyroxine. ${ }^{13}$ Prophylactic central lymph node dissection in primary surgery is not considered standard of care. ${ }^{14}$

Most patients with DTC experience no recurrence and have good prognosis after the primary treatment. Yet, according to several reports, the disease recurs in $5 \%-30 \%$ of patients within 10 years from the initial diagnosis, depending on the primary tumor stage and treatment modality.3,6,15-18 The most common pattern of failure is regional or cervical nodal recurrence, which is associated with an increased mortality rate of $7 \% .3,6$ The average time to regional recurrence is 2.6 years and ranges from 2 to 5 years from diagnosis (Table 1). These relapses most probably reflect persistence of microscopic disease at the lymphatic basins that was not detected before the initial operation. ${ }^{8}$

\section{DIAGNOSTIC WORK-UP FOR NODAL RECURRENCE IN DTC}

High-resolution ultrasound (US) and fine-needle aspiration-proven cytology are the mainstay modalities for the diagnosis of nodal recurrence. ${ }^{15}$ Serum thyroglobulin $(\mathrm{Tg})$ levels are routinely monitored to evaluate remission following surgery and adjuvant RAI treatment. Thyroglobulin is secreted exclusively by follicular thyroid cells, and elevated levels after total thyroidectomy and RAI therapy may suggest tumor recurrence.9,30,31 Stimulation of TSH enhances $\mathrm{Tg}$ assay sensitivity, but the impact of this test on patient outcome is controversial. ${ }^{13,30}$ Of note is that anti-Tg antibodies are detectable in $15 \%-20 \%$ of patients, ${ }^{13,32}$ and their presence interferes with $\mathrm{Tg}$ assessment. Whole-body iodine scans can also help the detection of regional and distant metastasis. 33

The use of CT and PET-CT in recurrent disease is less established. A recent study compared the roles of US, CT, and PET-CT in the evaluation of cervical recurrence in DTC, by correlating findings with final pathology. 34 The sensitivity, specificity, and accuracy were $69.2 \%, 89.7 \%$, and $80.0 \%$ for ultrasound; $63.5 \%, 94.8 \%$, and $80.0 \%$ for CT; and $53.8 \%, 79.3 \%$, and $67.3 \%$ for PET-CT, respectively. The sensitivity and specificity of ultrasound and CT were higher than for PET-CT. ${ }^{4}$ Still, PET-CT is a valid imaging modality for the diagnosis of iodine-negative lesions on iodine scan. 35

\section{RISK FACTORS FOR NODAL RECURRENCE}

Papillary thyroid cancer has a propensity for lymphoinvasion. The most established risk factor for lymph node recurrence in DTC is the presence of lymph node metastasis in the primary disease. ${ }^{36-39}$ Yet, there is still controversy whether microscopic lymph node metastasis in the primary disease holds the same risk for recurrence as does macroscopic metastasis. ${ }^{40}$ In a study of 545 patients with papillary thyroid cancer treated with surgery with or without RAI, the 10-year risk of lymph node recurrence was $19 \%$ in macroscopic nodal involvement and $4 \%$ in microscopic lymph node involvement. ${ }^{41}$ Extrathyroid extension at recurrence is associated with an increased risk of recurrence. ${ }^{19,38,39,41}$ Additional risk factors for nodal recurrence include male gender, tumor size of $>4 \mathrm{~cm}$, and elevated thyroglobulin levels measured 6-12 months after initial treatment. 41 
Table 1. Demographics and Treatment Modalities Reported by the Reviewed Studies.

\begin{tabular}{|c|c|c|c|c|c|c|c|c|c|c|c|}
\hline \multirow{2}{*}{ Author } & \multirow{2}{*}{ Year } & \multirow[t]{2}{*}{$n$} & \multirow{2}{*}{$\begin{array}{c}\text { Gender } \\
\text { F:M }\end{array}$} & \multirow{2}{*}{$\begin{array}{l}\text { Mean } \\
\text { Age } \\
(y)\end{array}$} & \multicolumn{2}{|c|}{ Site of LNR } & \multirow{2}{*}{$\begin{array}{c}\text { Mean } \\
\text { TTR } \\
\text { (mo) }\end{array}$} & \multicolumn{2}{|c|}{$\begin{array}{l}\text { Surgical } \\
\text { Treatment }\end{array}$} & \multicolumn{2}{|c|}{$\begin{array}{c}\text { Post-op } \\
\text { Treatment }\end{array}$} \\
\hline & & & & & Central & Lateral & & CCND & LCND & $\mid 131$ & RT \\
\hline Lango et al. ${ }^{19}$ & 2013 & 29 & $22: 7$ & 42 & 25 & 22 & $\mathrm{n} / \mathrm{a}$ & $\mathrm{n} / \mathrm{a}$ & $\mathrm{n} / \mathrm{a}$ & 29 & 3 \\
\hline Lang et al. ${ }^{20}$ & 2013 & 50 & $35: 15$ & 54.2 & 50 & 0 & 36.4 & 50 & 24 & 50 & 3 \\
\hline Tufano et al. ${ }^{21}$ & 2012 & 120 & $78: 42$ & 40.5 & 120 & 71 & 36 & 120 & $\mathrm{n} / \mathrm{a}$ & $\mathrm{n} / \mathrm{a}$ & $\mathrm{n} / \mathrm{a}$ \\
\hline Hughes et al. ${ }^{22}$ & 2012 & 61 & $42: 19$ & 40.7 & 61 & 0 & 24.7 & 31 & 50 & 13 & $\mathrm{n} / \mathrm{a}$ \\
\hline Shah et al. ${ }^{23}$ & 2012 & 82 & $57: 25$ & 42.6 & 82 & 41 & $\mathrm{n} / \mathrm{a}$ & 82 & 46 & 50 & $\mathrm{n} / \mathrm{a}$ \\
\hline Roh et al. ${ }^{24}$ & 2011 & 45 & $34: 11$ & 49.2 & 25 & 24 & 72 & 45 & 24 & $\mathrm{n} / \mathrm{a}$ & $\mathrm{n} / \mathrm{a}$ \\
\hline Clayman et al. ${ }^{25}$ & 2011 & 210 & $125: 85$ & 42 & 210 & 0 & 21 & 210 & 159 & 70 & 33 \\
\hline Yim et al. ${ }^{26}$ & 2011 & 83 & $59: 24$ & 42 & $\mathrm{n} / \mathrm{a}$ & $\mathrm{n} / \mathrm{a}$ & 27 & $\mathrm{n} / \mathrm{a}$ & 79 & 18 & $\mathrm{n} / \mathrm{a}$ \\
\hline Al-Saif et al. ${ }^{12}$ & 2010 & 60 & $48: 12$ & 41 & $\mathrm{n} / \mathrm{a}$ & $\mathrm{n} / \mathrm{a}$ & 36 & 60 & 57 & $\mathrm{n} / \mathrm{a}$ & $\mathrm{n} / \mathrm{a}$ \\
\hline Schuff et al. ${ }^{27}$ & 2008 & 74 & $54: 20$ & 47 & 74 & $\mathrm{n} / \mathrm{a}$ & $\mathrm{n} / \mathrm{a}$ & 74 & 64 & $\mathrm{n} / \mathrm{a}$ & $\mathrm{n} / \mathrm{a}$ \\
\hline Lee et al. ${ }^{28}$ & 2008 & 15 & $\mathrm{n} / \mathrm{a}$ & $\mathrm{n} / \mathrm{a}$ & $\mathrm{n} / \mathrm{a}$ & $\mathrm{n} / \mathrm{a}$ & $\mathrm{n} / \mathrm{a}$ & 8 & 7 & $\mathrm{n} / \mathrm{a}$ & $\mathrm{n} / \mathrm{a}$ \\
\hline Kim et al. ${ }^{29}$ & 2004 & 13 & $\mathrm{n} / \mathrm{a}$ & 49.4 & 13 & 0 & $\mathrm{n} / \mathrm{a}$ & 13 & 9 & $\mathrm{n} / \mathrm{a}$ & $\mathrm{n} / \mathrm{a}$ \\
\hline
\end{tabular}

CCND, central compartment neck dissection; F:M, female:male; LCND, lateral compartment neck dissection; LNR, lymph node recurrence; $n$, number of patients; $n / a$, not available; Post-op, postoperative; RT, radiotherapy; TTR (mo), time to recurrence (months); y, years.

\section{PATTERNS OF FAILURE}

Regional recurrence after total thyroidectomy most commonly involves the central neck compartment and, to a lesser extent, the lateral neck (Table 1).6,42 Lateral lymph node recurrence usually occurs in the ipsilateral side and more frequently involves levels II, III, and IV..$^{8}$ However, when lymph node metastasis is evident in the primary disease, involvement of level V should be assessed by ultrasonography. ${ }^{8}$

\section{SURGICAL MANAGEMENT OF NODAL RECURRENCE}

For persistent or recurrent nodal disease, the treatment modalities available include surgical treatment or RAI. However, in low- or intermediate-risk patients with nodes of less than $1 \mathrm{~cm}$, watchful waiting is a valid option.6,43 According to the 2015 American Thyroid Association (ATA) guidelines, the recommended management of suspected structural recurrence is neck dissection for patients with biopsy-proven persistent or recurrent disease greater than $8 \mathrm{~mm}$ in the central neck or $10 \mathrm{~mm}$ in the lateral neck, in the smallest dimension. $44 \mathrm{Lymph}$ node recurrence is usually characterized by welldefined masses isolated from the surrounding structures, in the absence of extracapsular extension. Recurrence at the thyroid bed is less organized and may involve the recurrent laryngeal nerve (RLN) or the trachea. ${ }^{14}$

Analysis of 100 patients who underwent neck dissection for recurrent nodal disease after RAI 45 showed that the negative predictive values of US for the specific levels were: level II, $66.2 \%$; level III, 49.4\%; level IV, 55.4\%; and level V, 88.5\%. Consequently, a formal lateral compartment neck dissecttion, including levels II-IV with or without level V, should be the routine practice for the management of nodal recurrence. 44,45

\section{MANAGEMENT OF THE CENTRAL NECK IN LATERAL NODAL RECURRENCE}

The primary echelons for malignant tumors of the thyroid are the paratracheal, pretracheal, and superior mediastinum lymph nodes (levels VI and VII). Palpable neck disease or radiological evidence of nodal metastases in DTC will necessitate therapeutic neck dissection; however, the rationale for prophylactic neck dissection remains debatable due to lack of level I evidence. Elective central neck dissection (CND) detects occult nodal metastases in 
$40 \%-60 \%$ of the remaining patients, whereas elective lateral neck dissection (LND) detects positive nodes in $40 \% .{ }^{46}$ Contralateral occult paratracheal nodes are evident in $10 \%-25 \%$ of patients. 47,48 When jugular chain metastases are present, the risk of central compartment metastases is higher. 49 Taken together, the overall risk of occult nodal metastases in patients with DTC according to some reports may reach $80 \% .{ }^{46}$ Based on these numbers alone, some surgeons have recommended prophylactic central neck dissection (ipsilateral or bilateral) in patients with DTC with clinically positive jugular nodes.50 However, no data in the literature show any clinical advantage of elective CND in this population..$^{11}$ As well, although postoperative complications of central neck dissection are relatively infrequent in experienced hands, hypocalcemia and vocal cord paralysis can lead to significant morbidity and impaired quality of life. $5^{2}$ Existing data show that prophylactic neck dissection does not influence early outcome of patients with DTC and that the risk of locoregional recurrence and distant metastases remains similar regardless of central nodes excision.53 Furthermore early tumor recurrence and disease-specific survival are not influenced by elective central neck dissection in patients with positive jugular chain nodes.54 Given the lack of objective benefit and a potential evidence of harm, prophylactic central neck dissection cannot be routinely recommended in this population.

\section{POSTOPERATIVE COMPLICATIONS}

Reoperation of the lateral or central neck is challenging due to scarring, fibrosis, and disruption of the normal anatomy. ${ }^{10,24,55,56}$ Table 2 summarizes the complications reported following reoperation for recurrent or persistent nodal disease in DTC.

The most common complications encountered in neck dissection for recurrent disease are vocal cord paralysis and hypoparathyroidism. 29,57 Transient vocal cord paralysis occurred in $0 \%-12 \%$ and permanent paralysis in $0 \%-5.8 \%$ of patients. The incidence of permanent hypocalcemia ranges between $0 \%$ and $9 \%$, and of transient hypocalcemia between $7 \%$ and $60 \% .10,55,58,59$ Other reported complications included chyle leak, surgical bed hematoma, and surgical site infection.

\section{SURGICAL OUTCOMES}

The primary outcomes following surgery include locoregional control and biochemical response. Biochemical response is defined as undetectable baseline or stimulated $\mathrm{Tg}$ levels in the absence of structural evidence of recurrence measured in the time period of 6-24 months following treatment.60 Five-year disease-free rates following reoperation reach 70\%.9,27 Complete biochemical response can be accomplished in about $21 \%$ of operated patients, while decreased $\mathrm{Tg}$ levels might reach $98 \%$ during a mean follow-up of 15.5 months. ${ }^{22} \mathrm{~A}$ follow-up period of up to 60 months might be needed to monitor complete biochemical response after surgery. ${ }^{12}$

\section{THE USE OF EBRT IN RECURRENT DTC}

The use of external beam radiotherapy (EBRT) in DTC is controversial, and its long-term benefits remain inconclusive. In a retrospective analysis at

Table 2. Reported Complication Rates after Reoperation for Lymph Node Recurrence.

\begin{tabular}{|c|c|c|c|c|c|c|c|c|}
\hline \multirow[b]{2}{*}{ Author } & \multirow[b]{2}{*}{ Year } & \multicolumn{7}{|c|}{ Complication Rates, $\boldsymbol{n}$ (\%) } \\
\hline & & $\begin{array}{c}\text { Transient } \\
\text { HC }\end{array}$ & $\begin{array}{c}\text { Permanent } \\
\text { HC }\end{array}$ & $\begin{array}{c}\text { Transient } \\
\text { VC Paralysis }\end{array}$ & $\begin{array}{l}\text { Permanent } \\
\text { VC Paralysis }\end{array}$ & $\begin{array}{l}\text { Chyle } \\
\text { Leak }\end{array}$ & Hematoma & Other* \\
\hline Lang et al. ${ }^{20}$ & 2013 & $7(14)$ & 0 & $6(12)$ & $1(2)$ & & & $2(4)$ \\
\hline Tufano et al. ${ }^{21}$ & 2012 & $12(10)$ & $3(2.5)$ & 0 & $7(5.8)$ & & & \\
\hline Hughes et al. ${ }^{22}$ & 2012 & $6(9.8)$ & 0 & 0 & $1(1.6)$ & $1(1.6)$ & & $2(3.2)$ \\
\hline Shah et al. ${ }^{23}$ & 2012 & $17(20.7)$ & $6(7.3)$ & $3(3.6)$ & $3(3.6)$ & & & \\
\hline Clayman et al. ${ }^{25}$ & 2011 & 0 & $2(0.9)$ & 0 & $4(1.9)$ & & & \\
\hline Schuff et al. ${ }^{27}$ & 2008 & $12(15.1)$ & $5(6.3)$ & $1(1.2)$ & 0 & & $9(11.3)$ & $1(1.2)$ \\
\hline Kim et al. ${ }^{29}$ & 2004 & $3(15)$ & $1(5)$ & 0 & 0 & & & \\
\hline
\end{tabular}

*Other complications included: seroma, esophageal injury, surgical site infection, and one intraoperative death. $\mathrm{HC}$, hypocalcemia; $n$, number; VC, vocal cord. 
the Memorial Sloan-Kettering Cancer Center of patients with DTC who received EBRT for locally advanced or recurrent extensive locoregional disease, the locoregional control rates were satisfactory taking into account the patients' originally poor prognosis. Acute adverse effects of EBRT included grade 3 acute mucositis and dysphagia, while late adverse toxicity included mainly the need for gastrostomy tube insertion in $5 \%$ of the patients. ${ }^{61}$

The 2015 ATA guidelines state that EBRT is to be considered in patients with non-resectable locoregional recurrences, or in cases of extranodal extension or involvement of soft tissue. They also recommend using EBRT in patients without evidence of distant metastasis. 44

\section{CONCLUSIONS}

Recurrent or persistent lymph node disease is the most common pattern of recurrence in DTC. The diagnosis is based mainly on US, Tg levels, and whole-body iodine scan. Nodal recurrence is best treated surgically when a structural lesion is evident. Surgery should be performed with intent to cure and includes a formal compartment neck dissection. Reoperation can be performed with low complication rates.

\section{REFERENCES}

1. Sherman SI. Thyroid carcinoma. Lancet 2003;361: 501-11. Full Text

2. Jossart GH, Clark OH. Well-differentiated thyroid cancer. Curr Probl Surg 1994;31:933-1012. Full Text

3. Hundahl SA, Fleming ID, Fremgen AM, Menck HR. A National Cancer Data Base report on 53,856 cases of thyroid carcinoma treated in the U.S., 1985-1995 [see comments]. Cancer 1998;83:2638-48. Full Text

4. Paterson IC, Greenlee R, Adams Jones D. Thyroid cancer in Wales 1985-1996: a cancer registry-based study. Clin Oncol (R Coll Radiol) 1999;11:245-51. Full Text

5. Davies L, Welch HG. Increasing incidence of thyroid cancer in the United States, 1973-2002. JAMA 2006; 295:2164-7. Full Text

6. Mazzaferri EL, Jhiang SM. Long-term impact of initial surgical and medical therapy on papillary and follicular thyroid cancer. Am J Med 1994;97:418-28. Full Text

7. Caron NR, Clark OH. Papillary thyroid cancer: surgical management of lymph node metastases. Curr Treat Options Oncol 2005;6:311-22. Full Text
8. Durante C, Montesano T, Torlontano M, et al. Papillary thyroid cancer: time course of recurrences during postsurgery surveillance. J Clin Endocrinol Metab 2013;98:636-42. Full Text

9. American Thyroid Association (ATA) Guidelines Taskforce on Thyroid Nodules and Differentiated Thyroid Cancer, Cooper DS, Doherty GM, et al. Revised American Thyroid Association management guidelines for patients with thyroid nodules and differentiated thyroid cancer. Thyroid 2009;19:1167214. Full Text

10. Alvarado R, Sywak MS, Delbridge L, Sidhu SB. Central lymph node dissection as a secondary procedure for papillary thyroid cancer: is there added morbidity? Surgery 2009;145:514-18. Full Text

11. White ML, Gauger PG, Doherty GM. Central lymph node dissection in differentiated thyroid cancer. World J Surg 2007;31:895-904. Full Text

12. Al-Saif O, Farrar WB, Bloomston M, Porter K, Ringel MD, Kloos RT. Long-term efficacy of lymph node reoperation for persistent papillary thyroid cancer. $J$ Clin Endocrinol Metab 2010;95:2187-94. Full Text

13. Kloos RT. Papillary thyroid cancer: medical management and follow-up. Curr Treat Options Oncol 2005;6:323-38. Full Text

14. Grant CS. Recurrence of papillary thyroid cancer after optimized surgery. Gland Surg 2015;4:52-62.

15. Cooper DS, Doherty GM, Haugen BR, et al. Management guidelines for patients with thyroid nodules and differentiated thyroid cancer. Thyroid 2006;16:10942. Full Text

16. Coburn M, Teates D, Wanebo HJ. Recurrent thyroid cancer. Role of surgery versus radioactive iodine (I131). Ann Surg 1994;219:587-93; discussion 593-5. Full Text

17. Schlumberger MJ. Diagnostic follow-up of welldifferentiated thyroid carcinoma: historical perspective and current status. J Endocrinol Invest 1999;22 (11 Suppl):3-7.

18. Grant CS, Hay ID, Gough IR, Bergstralh EJ, Goellner JR, McConahey WM. Local recurrence in papillary thyroid carcinoma: is extent of surgical resection important? Surgery 1988;104:954-62.

19. Lango M, Flieder D, Arrangoiz R, et al. Extranodal extension of metastatic papillary thyroid carcinoma: correlation with biochemical endpoints, nodal persistence, and systemic disease progression. Thyroid 2013;23:1099-105. Full Text

20. Lang BH, Lee GC, Ng CP, Wong KP, Wan KY, Lo CY. Evaluating the morbidity and efficacy of reoperative surgery in the central compartment for persistent/ recurrent papillary thyroid carcinoma. World J Surg 2013;37:2853-9. Full Text 
21. Tufano RP, Bishop J, Wu G. Reoperative central compartment dissection for patients with recurrent/ persistent papillary thyroid cancer: efficacy, safety, and the association of the BRAF mutation. Laryngoscope 2012;122:1634-40. Full Text

22. Hughes DT, Laird AM, Miller BS, Gauger PG, Doherty GM. Reoperative lymph node dissection for recurrent papillary thyroid cancer and effect on serum thyroglobulin. Ann Surg Oncol 2012;19:29517. Full Text

23. Shah MD, Harris LD, Nassif RG, Kim D, Eski S, Freeman JL. Efficacy and safety of central compartment neck dissection for recurrent thyroid carcinoma. Arch Otolaryngol Head Neck Surg 2012;138:337. Full Text

24. Roh JL, Kim JM, Park CI. Central compartment reoperation for recurrent/persistent differentiated thyroid cancer: patterns of recurrence, morbidity, and prediction of postoperative hypocalcemia. Ann Surg Oncol 2011;18:1312-18. Full Text

25. Clayman GL, Agarwal G, Edeiken BS, Waguespack SG, Roberts DB, Sherman SI. Long-term outcome of comprehensive central compartment dissection in patients with recurrent/persistent papillary thyroid carcinoma. Thyroid 2011;21:1309-16. Full Text

26. Yim JH, Kim WB, Kim EY, et al. The outcomes of first reoperation for locoregionally recurrent/persistent papillary thyroid carcinoma in patients who initially underwent total thyroidectomy and remnant ablation. J Clin Endocrinol Metab 2011;96:2049-56. Full Text

27. Schuff KG, Weber SM, Givi B, Samuels MH, Andersen PE, Cohen JI. Efficacy of nodal dissection for treatment of persistent/recurrent papillary thyroid cancer. Laryngoscope 2008;118:768-75. Full Text

28. Lee L, Steward DL. Sonographically-directed neck dissection for recurrent thyroid carcinoma. Laryngoscope 2008;118:991-4. Full Text

29. Kim MK, Mandel SH, Baloch Z, et al. Morbidity following central compartment reoperation for recurrent or persistent thyroid cancer. Arch Otolaryngol Head Neck Surg 2004;130:1214-16. Full Text

30. Gibelli B, Tredici P, De Cicco C, et al. Preoperative determination of serum thyroglobulin to identify patients with differentiated thyroid cancer who may present recurrence without increased thyroglobulin. Acta Otorhinolaryngol Ital 2005;25:94-9.

31. Mazzaferri EL, Robbins RJ, Spencer CA, et al. A consensus report of the role of serum thyroglobulin as a monitoring method for low-risk patients with papillary thyroid carcinoma J Clin Endocrinol Metab 2003;88:1433-41. Full Text
32. Moley JF, Lairmore TC, Doherty GM, Brunt LM, DeBenedetti MK. Preservation of the recurrent laryngeal nerves in thyroid and parathyroid reoperations. Surgery 1999;126:673-7; discussion 677-9. Full Text

33. Mazzaferri EL, Kloos RT. Is diagnostic iodine-131 scanning with recombinant human TSH useful in the follow-up of differentiated thyroid cancer after thyroid ablation? J Clin Endocrinol Metab 2002;87: 1490-8. Full Text

34. Seo YL, Yoon DY, Baek S, et al. Detection of neck recurrence in patients with differentiated thyroid cancer: comparison of ultrasound, contrast-enhanced CT and (18)F-FDG PET/CT using surgical pathology as a reference standard: (ultrasound vs. CT vs. (18)FFDG PET/CT in recurrent thyroid cancer). Eur Radiol 2012;22:2246-54. Full Text

35. Razfar A, Branstetter BF 4th, Christopoulos A, et al. Clinical usefulness of positron emission tomographycomputed tomography in recurrent thyroid carcinoma. Arch Otolaryngol Head Neck Surg 2010;136: 120-5. Full Text

36. Mazzaferri EL, Kloos RT. Clinical review 128: Current approaches to primary therapy for papillary and follicular thyroid cancer. J Clin Endocrinol Metab 2001;86:1447-63. Full Text

37. Grebe SK, Hay ID. Thyroid cancer nodal metastases: biologic significance and therapeutic considerations. Surg Oncol Clin N Am 1996;5:43-63.

38. Baek SK, Jung KY, Kang SM, et al. Clinical risk factors associated with cervical lymph node recurrence in papillary thyroid carcinoma. Thyroid 2010;20:147-52. Full Text

39. Leboulleux S, Rubino C, Baudin E, et al. Prognostic factors for persistent or recurrent disease of papillary thyroid carcinoma with neck lymph node metastases and/or tumor extension beyond the thyroid capsule at initial diagnosis. $J$ Clin Endocrinol Metab 2005;90:5723-9. Full Text

40. Bardet S, Ciappuccini R, Quak E, et al. Prognostic value of microscopic lymph node involvement in patients with papillary thyroid cancer. J Clin Endocrinol Metab 2015;100:132-40. Full Text

41. Bardet S, Malville E, Rame JP, et al. Macroscopic lymph-node involvement and neck dissection predict lymph-node recurrence in papillary thyroid carcinoma. Eur J Endocrinol 2008;158:551-60. Full $\underline{\text { Text }}$

42. Lundgren CI, Hall P, Dickman PW, Zedenius J. Clinically significant prognostic factors for differentiated thyroid carcinoma: a population-based, nested case-control study. Cancer 2006;106:524-31. $\underline{\text { Full Text }}$ 
43. Maxon HR, Thomas SR, Hertzberg VS, et al. Relation between effective radiation dose and outcome of radioiodine therapy for thyroid cancer. N Engl J Med 1983;309:937-41. Full Text

44. Haugen BRM, Alexander EK, Bible KC, et al. 2015 American Thyroid Association management guidelines for adult patients with thyroid nodules and differentiated thyroid cancer. Thyroid 2015 Oct 14. [Epub ahead of print]

45. Wu G, Fraser S, Pai SI, Farrag TY, Ladenson PW, Tufano RP. Determining the extent of lateral neck dissection necessary to establish regional disease control and avoid reoperation after previous total thyroidectomy and radioactive iodine for papillary thyroid cancer. Head Neck 2012;34:1418-21. Full Text

46. Wada N, Duh QY, Sugino K, et al. Lymph node metastasis from 259 papillary thyroid microcarcinomas: frequency, pattern of occurrence and recurrence, and optimal strategy for neck dissection. Ann Surg 2003;237:399-407. Full Text

47. Sadowski BM, Snyder SK, Lairmore TC. Routine bilateral central lymph node clearance for papillary thyroid cancer. Surgery 2009;146:696-703; discussion 703-5. Full Text

48. Roh JL, Kim JM, Park CI. Central lymph node metastasis of unilateral papillary thyroid carcinoma: patterns and factors predictive of nodal metastasis, morbidity, and recurrence. Ann Surg Oncol 2011;18: 2245-50. Full Text

49. Goropoulos A, Karamoshos K, Christodoulou A, et al. Value of the cervical compartments in the surgical treatment of papillary thyroid carcinoma. World $\mathrm{J}$ Surg 2004;28:1275-81. Full Text

50. Khafif A, Ben-Yosef R, Abergel A, Kesler A, Landsberg R, Fliss DM. Elective paratracheal neck dissection for lateral metastases from papillary carcinoma of the thyroid: is it indicated? Head Neck 2008;30:306-10. Full Text

51. Gil Z, Fliss DM. Contemporary management of head and neck cancers. Isr Med Assoc J 2009;11:296-300.

52. Gil Z, Patel SG. Surgery for thyroid cancer. Surg Oncol Clin N Am 2008;17:93-120, viii. Full Text
53. Shah MD, Hall FT, Eski SJ, Witterick IJ, Walfish PG, Freeman JL. Clinical course of thyroid carcinoma after neck dissection. Laryngoscope 2003;113:21027. Full Text

54. Trivizki O, Amit M, Fliss DM, Gil Z. Elective central compartment neck dissection in patients with papillary thyroid carcinoma recurrence. Laryngoscope 2013;1231564-8. Full Text

55. Shen WT, Ogawa L, Ruan D, et al. Central neck lymph node dissection for papillary thyroid cancer: comparison of complication and recurrence rates in 295 initial dissections and reoperations. Arch Surg 2010;145:272-5. Full Text

56. Roh JL, Park JY, Rha KS, Park CI. Is central neck dissection necessary for the treatment of lateral cervical nodal recurrence of papillary thyroid carcinoma? Head Neck 2007;29:901-6. Full Text

57. Chao TC, Jeng LB, Lin JD, Chen MF. Reoperative thyroid surgery. World J Surg 1997;21:644-7. Full Text

58. Mazzaferri EL, Doherty GM, Steward DL. The pros and cons of prophylactic central compartment lymph node dissection for papillary thyroid carcinoma. Thyroid 2009;19:683-9. Full Text

59. Pereira JA, Jimeno J, Miquel J, et al. Nodal yield, morbidity, and recurrence after central neck dissection for papillary thyroid carcinoma. Surgery 2005;138:1095-100, discussion 1100-1. Full Text

6o. Tuttle RM, Tala H, Shah J, et al. Estimating risk of recurrence in differentiated thyroid cancer after total thyroidectomy and radioactive iodine remnant ablation: using response to therapy variables to modify the initial risk estimates predicted by the new American Thyroid Association staging system. Thyroid 2010;20:1341-9. Full Text

61. Terezakis SA, Lee KS, Ghossein RA, et al. Role of external beam radiotherapy in patients with advanced or recurrent nonanaplastic thyroid cancer: Memorial Sloan-Kettering Cancer Center experience. Int $\mathrm{J}$ Radiat Oncol Biol Phys 2009;73:795-801. Full Text 